\title{
Germline $C D H 1$ mutations are a significant contributor to the high frequency of early-onset diffuse gastric cancer cases in New Zealand Māori
}

\author{
Christopher Hakkaart ${ }^{1} \cdot$ Lis Ellison-Loschmann ${ }^{2} \cdot$ Robert Day $^{1} \cdot$ Andrew Sporle $^{3}$. Jonathan Koea ${ }^{4}$. \\ Pauline Harawira $^{5} \cdot$ Soo Cheng $^{2} \cdot$ Michelle Gray $^{2} \cdot$ Tracey Whaanga $^{2} \cdot$ Neil Pearce $^{6} \cdot$ Parry Guilford $^{1}$
}

Published online: 27 March 2018

(c) The Author(s) 2018

\begin{abstract}
New Zealand Māori have a considerably higher incidence of gastric cancer compared to non-Māori, and are one of the few populations worldwide with a higher prevalence of diffuse-type disease. Pathogenic germline $\mathrm{CDH} l$ mutations are causative of hereditary diffuse gastric cancer, a cancer predisposition syndrome primarily characterised by an extreme lifetime risk of developing diffuse gastric cancer. Pathogenic $\mathrm{CDH} 1$ mutations are well described in Māori families in New Zealand. However, the contribution of these mutations to the high incidence of gastric cancer is unknown. We have used next-generation sequencing, Sanger sequencing, and Multiplex Ligation-dependent Probe Amplification to examine germline $\mathrm{CDH} 1$ in an unselected series of 94 Māori gastric cancer patients and 200 healthy matched controls. Overall, $18 \%$ of all cases, $34 \%$ of cases diagnosed with diffuse-type gastric cancer, and $67 \%$ of cases diagnosed aged less than 45 years carried pathogenic $\mathrm{CDH} 1$ mutations. After adjusting for the effect of screening known HDGC families, we estimate that $6 \%$ of all advanced gastric cancers and $13 \%$ of all advanced diffuse-type gastric cancers would carry germline $\mathrm{CDH} 1$ mutations. Our results demonstrate that germline $\mathrm{CDH} 1$ mutations are a significant contributor to the high frequency of diffuse gastric cancer in New Zealand Māori.
\end{abstract}

Keywords E-cadherin $\cdot \mathrm{CDH} 1 \cdot$ New Zealand $\cdot$ Māori $\cdot$ Hereditary diffuse gastric cancer $\cdot$ Genetic predisposition testing

\section{Introduction}

Although the worldwide incidence of gastric cancer has declined steadily over the past $4-5$ decades, it remains the 5 th most common cancer type worldwide [1]. The vast majority of gastric cancers are adenocarcinomas, which can be further subdivided into intestinal and diffuse type according to the Lauren classification [2]. Intestinal-type gastric cancer is more common in older patients and is more strongly associated with exposure to environmental risk factors, whereas diffuse-type gastric cancer is more associated with an earlier onset and a family history of the disease [2]. Typically, intestinal-type tumours predominate high-incidence geographic areas and account for much of the variation in gastric cancer incidence between groups [3].

As a whole, New Zealand is a country with a low incidence of gastric cancer [1]. However, Māori, the indigenous people of New Zealand (who comprise almost $15 \%$ of the total 4.5 million population) [4], experience disproportionate rates of gastric cancer compared to non-Māori [5]. The most 
recent data from the New Zealand Cancer Registry (NZCR) show Māori registration rates for gastric cancer are more than three times that of non-Māori (15.8 vs. 4.8 per 100,000, respectively) [6]. Additionally, on average, Māori develop gastric cancer 10 years younger than non-Māori and are one of the few populations worldwide with a higher incidence of diffuse-type disease [7, 8]. The reasons for these differences are largely unexplained.

Germline mutations in the gene $C D H I$, encoding the cell adhesion protein E-cadherin, are causative of the autosomal dominant cancer predisposition syndrome Hereditary Diffuse Gastric Cancer (HDGC) [9, 10]. Mutation carriers are predisposed to an extreme risk of developing diffuse-type gastric cancer from a relatively young age [11]. Based on HDGC families from around the world, the current estimated cumulative risk of developing diffuse gastric cancer by the age of 80 years is $70 \%$ for males (95\% CI 59-80\%) and $56 \%$ for females (95\% CI 44-69\%) [11]. In addition, women carrying $\mathrm{CDH} 1$ mutations have a $42 \%$ (95\% CI 23-68\%) cumulative risk of developing lobular breast cancer by the age of 80 years [11]. In Family A, the large Māori kindred in which the first pathogenic $\mathrm{CDH} 1$ mutation was identified, the overall penetrance of diffuse gastric cancer is approximately $70 \%$ [9]. In Western populations, it is estimated that $1 \%$ of all gastric cancers are caused by germline $\mathrm{CDH} 1$ mutations [12].

Germline $\mathrm{CDH} 1$ mutations have been well documented in Māori families in New Zealand [8, 9]. However, the contribution $\mathrm{CDH} 1$ mutations make to the high incidence of diffuse gastric cancer in Māori is unknown. This paper presents the findings on the prevalence of cases with pathogenic $\mathrm{CDH} 1$ mutations from a case-control study of gastric cancer conducted in the Māori population.

\section{Materials and methods}

\section{Study participants}

Study participants were from a New Zealand Māori population-based case-control study examining factors associated with gastric cancer risk [13]. Briefly, all Māori gastric cancers reported to the NZCR between 1 February 2009 and 31 October 2013 were followed up, with a sample of whole blood obtained from consenting participants who were well enough. The control group were a populationbased random sample of individuals aged over 18 years who self-identified as Māori on the New Zealand electoral roll. Sequenced controls were matched to cases by gender and 5 year age bands. The study was granted ethics approval by the New Zealand Multi-region Ethics Committee (ref: MEC/08/08/102/AM03). Informed written consent was obtained from all study participants. Full details describing the identification of study participants and the collection of samples are described in Ellison-Loschmann et al. [13].

\section{Sequencing library preparation}

Duel-indexed amplicon sequencing libraries for germline $\mathrm{CDHl}$ were generated using a novel two-step PCR strategy. Briefly, in the first PCR step, the coding exons of $\mathrm{CDHl}$, including their intron-exon borders and the proximal promoter, were amplified. $\mathrm{CDH} 1$ primers were designed with an additional $18 \mathrm{bp}$ of known non-specific sequence that was used as a priming site for the second reaction (Supplementary Table 1). PCR products from the same study participant were pooled in equal volumes and purified using AMPure XP beads. In the second PCR step, pooled PCR products were amplified using a unique pair of indexed primers designed to add sequences necessary for multiplex sequencing on an Illumina MiSeq (Supplementary Table 2). Full details describing the PCR reactions are available upon request.

Sample specific libraries were pooled and sequenced in batches across multiple MiSeq runs. To prepare the sequencing libraries, sample libraries were pooled in equal volumes, purified using AMPure XP beads, and quantified with the Qubit dsDNA HS Assay Kit. Sequencing libraries were run on a DNA7500 Bioanlayzer chip to determine the average library size. Libraries were sequenced on an Illumina MiSeq using either V2-500 cycle or V3-600 cycle reagent kits.

\section{Sequence analysis and annotation}

Raw paired end reads were cleaned with Trimmomatic v.0.35 [14]. Cleaned reads were aligned to the human reference genome (GRCh37/hg19) using the Burrows-Wheeler Aligner v.0.7.10 [15]. Amplicons were sequenced to a minimum depth of 40 reads. Any amplicon that did not reach this threshold was sequenced again in a subsequent MiSeq run or Sanger sequenced. Single nucleotide variants and insertion/ deletion variants were called using 'The Genome Analysis Toolkit' (GATK) v.3.6 [16]. The effects of variants were predicted using SnpEff v.4.2 [17]. Variants were annotated with minor allele frequencies from the Exome Aggregation Consortium (ExAC) [18], the 1000 Genomes Project [19], and the University of Washington's Exome Sequencing Project (ESP6500) [20] databases. The functional consequences of missense variants were predicted in silico using SIFT [21], Provean [22], and PolyPhen2 [23].

\section{Classification on pathogenic variants}

Nonsynonymous and noncoding variants with a minor allele frequency (MAF) of $<0.05$ for cases or controls were considered rare. All rare variants were queried in ClinVar 
and published literature, and were classified according to the American College of Medical Genetics and Genomics guidelines [24].

\section{Variant validation}

All rare variants were visually inspected using the Integrative Genomics Viewer [25]. Rare nonsynonymous and noncoding variants were confirmed by re-extracting DNA from blood samples and Sanger sequencing.

\section{Copy number analysis}

Cases without pathogenic $C D H 1$ mutations were subsequently tested for copy number changes using Multiplex Ligation Dependent Probe Amplification (MLPA). The SALSA MLPA $C D H 1$ probe-mix (v.C1) was used according to the manufacturer's instructions. Results were analysed using Coffalyser.Net software.

\section{Statistical analysis}

Statistical tests were performed using R v.3.3.3 [26]. The significance of correlation between clinical characteristics and mutation status were tested using Fisher's exact test.

\section{Results}

\section{Characteristics of study participants}

Germline $\mathrm{CDH} 1$ was sequenced for 94 Māori gastric cancer patients and 200 healthy matched controls. The cases comprised $50(53 \%)$ males and $44(47 \%)$ females. The average age of cases at the time of gastric cancer diagnosis was 55.5 years (range 17-81 years). Tumour histology was available for $81 / 94$ (86.2\%) of cases. Out of these 81 cases, $50(62 \%)$ were diffuse type, $22(27 \%)$ were intestinal type, and $9(11 \%)$ were other types. Of the 21 cases diagnosed in individuals younger than 45 years, 20 (95\%) were diffuse type and one (5\%) was unspecified (Fig. 1). The earliest intestinal-type tumour was diagnosed in a patient aged 49 years. The full clinical characteristics of the cases are presented in Table 1.

Pathology reports from cases were reviewed for information that indicated prior genetic screening. Pathology reports from 15 cases described prophylactic gastrectomies, endoscopic screening, or noted $\mathrm{CDH} 1$ mutation status as a part of the clinical pathway. As these procedures are offered to $\mathrm{CDHl}$ mutation carriers, it is likely these cases were known mutation carriers who had elected prophylactic surgery or who had foci of gastric cancer identified during endoscopic screening.

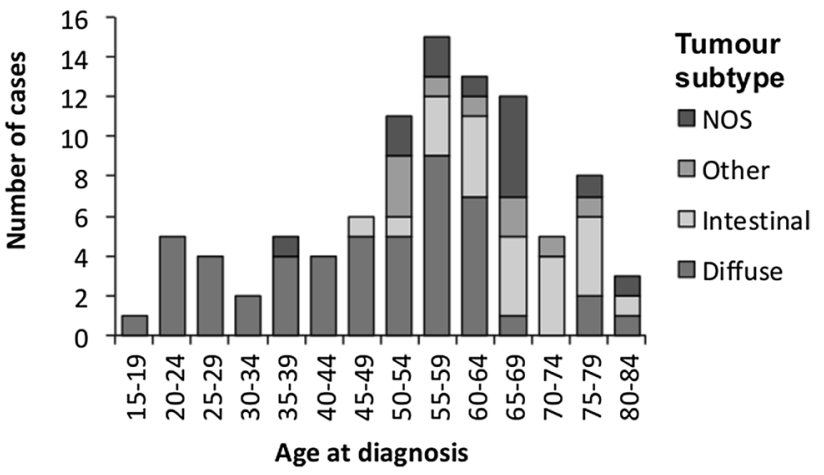

Fig. 1 Tumour subtypes by age at diagnosis of gastric cancer in cases. NOS not otherwise specified

Table 1 Clinical characteristics of the study cases

\begin{tabular}{|c|c|c|}
\hline & \multicolumn{2}{|c|}{ Total } \\
\hline & $\mathrm{n}$ & $\%$ \\
\hline Total & 94 & \\
\hline \multicolumn{3}{|l|}{ Gender } \\
\hline Male & 50 & 53 \\
\hline Female & 44 & 47 \\
\hline \multicolumn{3}{|l|}{ Age at diagnosis (years) } \\
\hline$<45$ & 21 & 22 \\
\hline $45-59$ & 32 & 34 \\
\hline $60-74$ & 30 & 32 \\
\hline$>75$ & 11 & 12 \\
\hline \multicolumn{3}{|l|}{ Tumour subtype } \\
\hline Diffuse & 50 & 53 \\
\hline Intestinal & 22 & 23 \\
\hline Other & 9 & 10 \\
\hline NOS & 13 & 14 \\
\hline \multicolumn{3}{|l|}{ Tumour grade } \\
\hline Well differentiated & 4 & 4 \\
\hline Moderately differentiated & 10 & 11 \\
\hline Poorly differentiated & 47 & 50 \\
\hline NOS & 33 & 35 \\
\hline \multicolumn{3}{|l|}{ Tumour site } \\
\hline Proximal & 30 & 32 \\
\hline Distal & 20 & 21 \\
\hline Mixed & 4 & 4 \\
\hline Oesophageal junction & 5 & 5 \\
\hline NOS & 35 & 37 \\
\hline \multicolumn{3}{|l|}{ Extent } \\
\hline Local & 26 & 28 \\
\hline Lymph node involvement & 20 & 21 \\
\hline Regional spread & 7 & 7 \\
\hline Metastatic spread & 13 & 14 \\
\hline NOS & 28 & 30 \\
\hline
\end{tabular}

NOS, not otherwise specified 
The controls comprised 104 (52\%) males and 96 (48\%) females. The average age of the controls was 57.6 years (range 19-84 years).

\section{Variants of uncertain significance}

Four healthy controls were found to carry one of three variants of uncertain significance (c.88C $>A$ (p.Pro30Thr), c.1214A $>$ G (p.Asn405Thr), and c.2556G $>$ T (p.Glu852Asp); Supplementary Table 3). To our knowledge, this is the first time these variants have been reported in the Māori population. No variants of uncertain significance were identified in the gastric cancer cases.

CDH1 c. $88 \mathrm{C}>\mathrm{A}$ was identified in one healthy control aged 56 years. c. $88 \mathrm{C}>\mathrm{A}$ has been reported in population databases (MAF $\leq 0.001)$ and is most commonly classified as 'likely benign' in Clin Var. In silico prediction tools have conflicting interpretations of $\mathrm{CDH} 1 \mathrm{c} .88 \mathrm{C}>\mathrm{A}$ pathogenicity. Notably, germline $\mathrm{CDH} 1 \mathrm{c} .88 \mathrm{C}>\mathrm{A}$ has been reported in lobular breast and diffuse gastric cancer patients [27, 28], as well as two unrelated individuals with cleft lip with or without cleft palate, a developmental birth defect that is known to be overrepresented in $\mathrm{CDH} 1$ mutation carriers [29, 30]. Additional evidence from in vitro assays indicate that the p.Pro30Thr mutation affects E-cadherin protein function and its subcellular localisation [30].

CDH1 c. $1214 \mathrm{~A}>\mathrm{G}$ (p.Asn405Ser) was identified in one healthy control (age 74 years) and c.2556G $>\mathrm{T}$
(p.Glu852Asp) was identified in two healthy controls (age 62 and 68 years). Both c. $1214 \mathrm{~A}>\mathrm{G}$ and c. $2556 \mathrm{G}>\mathrm{T}$ are very rare in population variant databases $(\mathrm{MAF}<0.0001)$ and are not described in published literature. In silico predictions do not support a pathogenic classification for either of these mutations.

\section{Pathogenic mutations}

After reviewing all available information regarding the variants identified in this study, we classified five variants as pathogenic mutations (three nonsense, one frameshift, and one missense; Supplementary Table 4). The three nonsense mutations (c.190C > T (p.Gln64*), c. 1792C > T (p.Arg598*), and c. $2287 \mathrm{G}>\mathrm{T}$ (p.Glu763*)) and one frameshift mutation (c.2381_2386insC (p.Arg796fs)) were identified in four cases each, while the deleterious missense mutation (c.2195G >A (p.Arg763Gln)) was identified in a single case (Table 2). The nonsense and frameshift mutations are known HDGC mutations that had previously been reported in Māori families in New Zealand [31]. c.2195G $>\mathrm{A}$ is a putative HDGC mutation that is located at the intracellular border of the cytoplasmic domain of E-cadherin and has been shown to create a new acceptor splice site and a large deletion in the E-cadherin protein [32]. c.2195G >A had previously been shown to be causative of HDGC in two families of northern European origin [33]. To our knowledge, this is the first time

Table 2 Clinical characteristics of Māori gastric cancer patients with pathogenic germline $C D H 1$ mutations

\begin{tabular}{|c|c|c|c|c|c|c|c|c|}
\hline Identifier & $\mathrm{Age}^{\mathrm{a}}$ & Gender & Nucleotid change $^{b}$ & Protein change $^{b}$ & Subtype & Extent & Grade & Site \\
\hline $\mathrm{Y} 240$ & 24 & Female & c. $190 \mathrm{C}>\mathrm{T}$ & p.Gln64* & Diffuse & Local & NOS & NOS \\
\hline Y382 & 29 & Male & c. $190 \mathrm{C}>\mathrm{T}$ & p.Gln64* & Diffuse & Local & NOS & Proximal \\
\hline Y704 & 48 & Female & c. $190 \mathrm{C}>\mathrm{T}$ & p.Gln64* & Diffuse & Local & NOS & NOS \\
\hline Y647 & 61 & Female & c. $190 \mathrm{C}>\mathrm{T}$ & p.Gln64* & Diffuse & Local & NOS & Distal \\
\hline Y649 & 20 & Female & c. $1792 \mathrm{C}>\mathrm{T}$ & p.Arg598* & Diffuse & Local & NOS & NOS \\
\hline Y579 & 23 & Female & c. $1792 \mathrm{C}>\mathrm{T}$ & p.Arg598* & Diffuse & Local & NOS & NOS \\
\hline Y709 & 24 & Male & c. $1792 \mathrm{C}>\mathrm{T}$ & p.Arg598* & Diffuse & Local & Poorly differentiated & Proximal \\
\hline Y255 & 29 & Female & c. $1792 \mathrm{C}>\mathrm{T}$ & p.Arg598* & Diffuse & Local & NOS & Proximal \\
\hline Y616 & 38 & Female & c. $2195 \mathrm{G}>\mathrm{A}$ & p.Arg732Gln & Diffuse & Metastatic spread & Poorly differentiated & NOS \\
\hline Y435 & 31 & Female & c. $2287 \mathrm{G}>\mathrm{T}$ & p.Glu763* & Diffuse & Local & Poorly differentiated & Proximal \\
\hline Y670 & 39 & Female & c. $2287 \mathrm{G}>\mathrm{T}$ & p.Glu763* & Diffuse & Metastatic spread & NOS & NOS \\
\hline Y706 & 41 & Male & c. $2287 \mathrm{G}>\mathrm{T}$ & p.Glu763* & Diffuse & Local & NOS & NOS \\
\hline Y335 & 50 & Male & c. $2287 \mathrm{G}>\mathrm{T}$ & p.Glu763* & Diffuse & Local & NOS & NOS \\
\hline Y638 & 17 & Male & c.2381_2386insC & p.Arg796fs & Diffuse & Local & NOS & NOS \\
\hline Y425 & 20 & Male & c.2381_2386insC & p.Arg796fs & Diffuse & Local & NOS & NOS \\
\hline Y666 & 26 & Female & c.2381_2386insC & p.Arg796fs & Diffuse & Local & NOS & NOS \\
\hline Y386 & 44 & Male & c.2381_2386insC & p.Arg796fs & Diffuse & Local & NOS & NOS \\
\hline
\end{tabular}

NOS not otherwise specified

${ }^{a}$ Age at time of diagnosis

${ }^{\text {b}}$ Variant positions are reported in reference to NCBI RefSeq NM_004360.3 (mRNA) and NP_004351.1 (protein) 
c. $2195 \mathrm{G}>\mathrm{A}$ has been reported in New Zealand Māori. No pathogenic mutations were identified in the controls.

\section{Frequency of pathogenic mutations}

Overall, pathogenic germline $\mathrm{CDH} 1$ mutations were identified in 17/94 (18\%) of the total gastric cancer cases and $17 / 50$ (34\%) of diffuse gastric cancer cases (Table 3). The proportion of cases aged less than 45 years at diagnosis with a pathogenic germline CDH1 mutation was 14/21 (67\%). Only $3 / 73(4 \%)$ of cases with mutations were aged 45 years and over (Fig. 2). The average age of diagnosis for mutation carriers was 33.2 years (range 17-61), and 60 years (range

Table 3 Clinical characteristics of the study cases by mutation status

\begin{tabular}{|c|c|c|c|c|c|}
\hline & \multicolumn{2}{|c|}{$\begin{array}{l}\mathrm{CDH1} \\
\text { mutation } \\
\text { positive }\end{array}$} & \multicolumn{2}{|c|}{$\begin{array}{l}C D H 1 \text { muta- } \\
\text { tion negative }\end{array}$} & \multirow[t]{2}{*}{$\mathrm{p}$ value } \\
\hline & $\mathrm{n}$ & $\%$ & $\mathrm{n}$ & $\%$ & \\
\hline Total & 17 & 18 & 77 & 82 & \\
\hline \multicolumn{6}{|l|}{ Gender } \\
\hline Male & 7 & 14 & 43 & 86 & \\
\hline Female & 10 & 23 & 34 & 77 & 0.296 \\
\hline \multicolumn{6}{|l|}{ Age at diagnosis (years) } \\
\hline$<45$ & 14 & 67 & 7 & 33 & \\
\hline $45-59$ & 2 & 6 & 30 & 94 & \\
\hline $60-74$ & 1 & 3 & 29 & 97 & \\
\hline$>75$ & 0 & 0 & 11 & 100 & $<0.001$ \\
\hline \multicolumn{6}{|l|}{ Tumour subtype } \\
\hline Diffuse & 17 & 34 & 33 & 66 & \\
\hline Intestinal & 0 & 0 & 22 & 100 & \\
\hline Other & 0 & 0 & 9 & 100 & \\
\hline NOS & 0 & 0 & 13 & 100 & $<0.001$ \\
\hline \multicolumn{6}{|l|}{ Tumour grade } \\
\hline Well differentiated & 0 & 0 & 4 & 100 & \\
\hline Moderately differentiated & 0 & 0 & 10 & 100 & \\
\hline Poorly differentiated & 3 & 6 & 44 & 94 & \\
\hline NOS & 14 & 42 & 19 & 58 & $<0.001$ \\
\hline \multicolumn{6}{|l|}{ Tumour site } \\
\hline Proximal & 4 & 13 & 26 & 87 & \\
\hline Distal & 1 & 5 & 19 & 95 & \\
\hline Mixed & 0 & 0 & 4 & 100 & \\
\hline Oesophageal junction & 0 & 0 & 5 & 100 & \\
\hline NOS & 12 & 34 & 23 & 66 & 0.048 \\
\hline \multicolumn{6}{|l|}{ Extent } \\
\hline Local & 15 & 58 & 11 & 42 & \\
\hline Lymph node involvement & 0 & 0 & 20 & 100 & \\
\hline Regional spread & 0 & 0 & 7 & 100 & \\
\hline Metastatic spread & 2 & 15 & 11 & 85 & \\
\hline NOS & 0 & 0 & 28 & 100 & $<0.001$ \\
\hline
\end{tabular}

NOS not otherwise specified

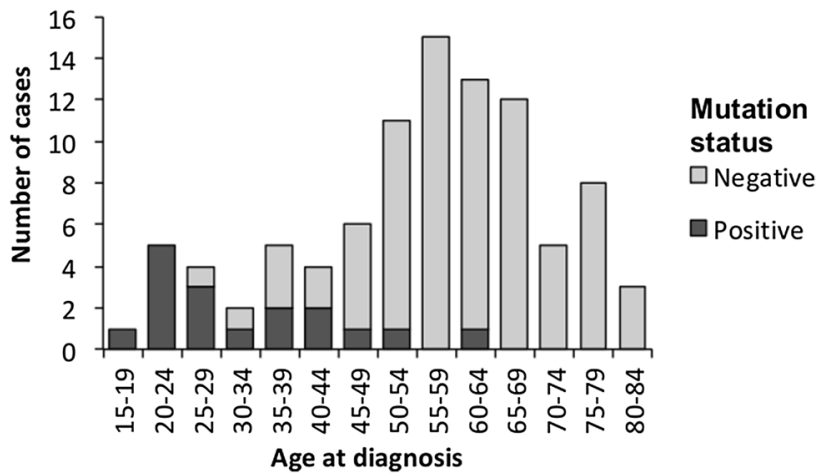

Fig. 2 Frequency of pathogenic germline $C D H 1$ mutations by age at diagnosis of gastric cancer in cases

28-81) for non-carriers. Of the pathogenic mutation carriers, $15 / 17$ (88\%) were diagnosed with early stage localised tumours, presumably subsequent to HDGC family mutation screening. The remaining two cases with pathogenic mutations were diagnosed with late stage metastatic disease and did not appear to be diagnosed as a result of being a known $\mathrm{CDHl}$ mutation carrier.

Our data demonstrates that between 2009 and 2013, 18 and 34\% of Māori gastric cancer and diffuse gastric cancer cases, respectively, carried pathogenic germline $\mathrm{CDH} I$ mutations. However, since the majority of these cases were diagnosed as a result of prior familial HDGC screening, these figures do not accurately represent the prevalence of pathogenic $C D H 1$ mutations in the Māori gastric cancer population. Without the targeted interventions offered to the 15 cases that were likely diagnosed as a result of being a known $C D H 1$ mutation carrier, it is unlikely they would have presented until their cancers had progressed and symptoms emerged. Accordingly, without prior genetic screening, the majority of $\mathrm{CDHI}$ mutation carriers identified during this study would have likely presented with advanced disease at a later date. Accounting for the number of Māori CDH1 mutation carriers identified between 1998 and 2008 (P. Guilford, personal communication) and using a lifetime penetrance estimate of $70 \%$, we estimate that in the absence of familial HDGC screening, germline $\mathrm{CDH} 1$ mutations would account for $6 \%$ of all advanced Māori gastric cancers and $13 \%$ of all diffuse-type gastric cancers.

\section{Discussion}

To our knowledge, this is the first study that has examined the frequency of gastric cancers that are attributable to germline $\mathrm{CDH} 1$ mutations in a specific ethnic group. In keeping with previous studies, we observed a high proportion of diffuse gastric cancers, many of which were diagnosed in patients less than 45 years of age. Overall, $18 \%$ of all cases, 
$34 \%$ of cases diagnosed with diffuse-type gastric cancer, and $67 \%$ of cases diagnosed aged less than 45 years carried pathogenic $\mathrm{CDH} 1$ mutations. Additionally, we estimate that in absence of screening, $6 \%$ of all advanced gastric cancer and $13 \%$ of all advanced diffuse-type gastric cancers in the Māori population would carry germline $\mathrm{CDH} 1$ mutations.

Whether any of the variants of uncertain significance identified in healthy controls in this study impact on E-cadherin function and, consequently, have a role in gastric cancer predisposition remains to be clarified. In particular, the c. $88 \mathrm{C}>\mathrm{A}$ (p.Pro30Thr) mutation will require further evaluation to determine if it is associated with a hereditary cancer risk. Given the relative frequency of c. $88 \mathrm{C}>\mathrm{A}$ in the healthy population it is unlikely to be associated with an extreme risk of disease. However, as c. $88 \mathrm{C}>\mathrm{A}$ has been identified in unrelated cleft lip with or without cleft palate cases, and has been shown to cause defects in E-cadherin protein function and its subcellular localisation in vitro, it is plausible that the $c .88 \mathrm{C}>\mathrm{A}$ mutation has a deleterious effect on E-cadherin function in vivo and may represent a mutation with a low to moderate risk of disease.

It is unclear why the prevalence of pathogenic germline $\mathrm{CDH} 1$ mutations is so high in the Māori gastric cancer population. Founder mutations have been identified as a common cause of cancer in some populations. Of note is the Ashkenazi Jewish population, for which approximately $2 \%$ of the general population carry one of three founder mutations in the tumour suppressor genes BRCA1 and BRCA2 [34]. Mutations in these genes are associated with an increased risk of both breast and ovarian cancer [35]. Subsequently, approximately $12 \%$ of breast cancers [36] and $40 \%$ [37] of ovarian cancers in the Ashkenazi Jewish population are attributable to these specific founder mutations. Similarly, a founder mutation in germline $\mathrm{CDH} I$ has previously been identified in multiple families from Newfoundland, Canada [32]. Interestingly, Newfoundland has an elevated rate of gastric cancer compared to the Canadian average and the regions these families come from are the highest-risk areas within the province $[32,38]$. As yet, the exact contribution of $\mathrm{CDH} 1$ mutations to the high rates of gastric cancer in the Newfoundland province is still to be determined.

Similar to the common mutation seen in Newfoundland, $\mathrm{CDH} 1$ mutations could have arisen as founder mutations prior to the Māori migration to New Zealand. However, the relatively high number of distinct $\mathrm{CDH} 1$ mutations (5 mutations in this study alone) suggests that, rather than being an illustration of a simple genetic bottleneck, $\mathrm{CDH} 1$ mutations may have provided a selective advantage to mutation carriers in ancestral Māori populations.

One possible explanation is that $\mathrm{CDH} 1$ mutation carriers may have a degree of innate resistance to infection with Listeria monocytogenes, a food-born pathogen that can cause gastroenteritis, meningitis, and miscarriage in pregnant women $[39,40]$. L. monocytogenes is normally internalised into epithelial cells by a process requiring the binding of the bacterial protein internalin-A (InlA) to the N-terminus of the E-cadherin protein [40]. Some truncating E-cadherin mutations produce short soluble $\mathrm{N}$-terminal peptides containing the InlA binding site that have been shown to act as decoy receptors for invading $L$. monocytogenes in vitro [39]. Alternatively, a reduction in functional E-cadherin available in mutation carriers may cause changes to the organisation of the cortical actin cytoskeleton which, in turn, may impact on the efficiency of endocytosis and the internalisation of $L$. monocytogenes or other pathogens [41].

The main purpose of our study was to determine the prevalence of pathogenic $C D H 1$ mutations in the Māori gastric cancer population. After reviewing the pathology reports from gastric cancer cases, the importance and impact of genetic screening for Māori became especially apparent. Notably, all 15 gastric cancer cases that were diagnosed as a result of interventions available to known $\mathrm{CDH} 1$ mutation carriers were diagnosed with early-stage disease and were still alive five years post diagnosis (data not shown). In contrast, the two $C D H 1$ mutation carriers who did not appear to be known carriers were both diagnosed with late-stage metastatic disease and both died shortly after diagnosis. Clearly, clinical genetic screening and targeted interventions for $\mathrm{CDH} \mathrm{l}$ mutation carriers is enabling timely and effective identification and management of mutation carriers in known HDGC families. Our findings suggest that, ideally, clinical germline $\mathrm{CDH} 1$ testing should be incorporated into standard care for all Māori who present with early-onset diffuse gastric cancer.

As the most comprehensive study of germline $\mathrm{CDHI}$ mutations in a specific ethnic group, our study demonstrates the significant impact pathogenic $\mathrm{CDH} 1$ mutations have on the high frequency of early-onset diffuse gastric cancer cases in the New Zealand Māori population. We highlight the importance of clinical genetic screening of HDGC families and the potential benefits of genetically screening all Māori who present with early-onset diffuse gastric cancer.

Acknowledgements The authors would like to thank all the study participants and their families, the staff at the New Zealand Cancer Registry, and all the support staff involved in this research. The study was funded by a project grant (HRC 08/258) from the Māori Committee of the Health Research Council of New Zealand. The Centre for Public Health Research is supported by a Programme Grant from the Health Research Council of New Zealand. C. Hakkaart was supported by a University of Otago doctoral fellowship.

\section{Compliance with ethical standards}

Conflict of interest The authors have no conflicts of interest to declare. 
Open Access This article is distributed under the terms of the Creative Commons Attribution 4.0 International License (http://creativeco mmons.org/licenses/by/4.0/), which permits unrestricted use, distribution, and reproduction in any medium, provided you give appropriate credit to the original author(s) and the source, provide a link to the Creative Commons license, and indicate if changes were made.

\section{References}

1. Ferlay J, Soerjomataram I, Dikshit R, Eser S, Mathers C, Rebelo M, Parkin DM, Forman D, Bray F (2015) Cancer incidence and mortality worldwide: sources, methods and major patterns in GLOBOCAN 2012. Int J Cancer 136(5):E359-E386

2. Lauren $P$ (1965) The two histological main types of gastric carcinoma: diffuse and so-called intestinal-type carcinoma. An attempt at a histo-clinical classification. Acta Pathol Microbiol Scand 64:31-49

3. Hartgrink HH, Jansen EP, van Grieken NC, van de Velde CJ (2009) Gastric cancer. Lancet 374(9688):477-490

4. Ministry of Social Development (2016) The social report 2016-Te pūrongo oranga tangata. Ministry of Social Development, Wellington

5. Teng AM, Atkinson J, Disney G, Wilson N, Sarfati D, McLeod M, Blakely T (2016) Ethnic inequalities in cancer incidence and mortality: census-linked cohort studies with 87 million years of person-time follow-up. BMC Cancer 16(1):755

6. Ministry of Health (2015) Cancer: new registrations and deaths 2012. Ministry of Health, Wellington

7. Biggar M, Srinivasa S, Wickramarachchi B, Babor R, Poole GH, Hill AG (2011) Gastric cancer location and histological subtype in Pacific people and Māori defies international trends. J N Z Med Assoc 124:1331

8. Blair V, Charlton A, Sutton T, Martin I (2003) High incidence of 'diffuse type'sporadic gastric cancer in Maori New Zealanders: possible evidence of further cancer susceptibility in addition to the known truncating germline E-caderin mutations in Maori families with hereditary diffuse gastric cancer? Gastroenterology 124(4):A548

9. Guilford P, Hopkins J, Harraway J, McLeod M (1998) E-cadherin germline mutations in familial gastric cancer. Nature 392(6674):402

10. van der Post RS, Vogelaar IP, Carneiro F, Guilford P, Huntsman D, Hoogerbrugge N, Caldas C, Schreiber KEC, Hardwick RH, Ausems MG (2015) Hereditary diffuse gastric cancer: updated clinical guidelines with an emphasis on germline CDH1 mutation carriers. J Med Genet 52(6):361-374

11. Hansford S, Kaurah P, Li-Chang H, Woo M, Senz J, Pinheiro H, Schrader KA, Schaeffer DF, Shumansky K, Zogopoulos G (2015) Hereditary diffuse gastric cancer syndrome: CDH1 mutations and beyond. JAMA Oncol 1(1):23-32

12. Blair V, Martin I, Shaw D, Winship I, Kerr D, Arnold J, Harawira P, McLeod M, Parry S, Charlton A (2006) Hereditary diffuse gastric cancer: diagnosis and management. Clin Gastroenterol Hepatol 4(3):262-275

13. Ellison-Loschmann L, Sporle A, Corbin M, Cheng S, Harawira P, Gray M, Whaanga T, Guilford P, Koea J, Pearce N (2017) Risk of stomach cancer in Aotearoa/New Zealand: a Māori population based case-control study. PLoS ONE 12(7):e0181581

14. Bolger AM, Lohse M, Usadel B (2014) Trimmomatic: a flexible trimmer for illumina sequence data. Bioinformatics 30(15):2114-2120

15. Li H, Durbin R (2009) Fast and accurate short read alignment with Burrows-Wheeler transform. Bioinformatics 25(14):1754-1760
16. McKenna A, Hanna M, Banks E, Sivachenko A, Cibulskis K, Kernytsky A, Garimella K, Altshuler D, Gabriel S, Daly M (2010) The genome analysis toolkit: a MapReduce framework for analyzing next-generation DNA sequencing data. Genome Res 20(9):1297-1303

17. Cingolani P, Platts A, Wang LL, Coon M, Nguyen T, Wang L, Land SJ, Lu X, Ruden DM (2012) A program for annotating and predicting the effects of single nucleotide polymorphisms, SnpEff: SNPs in the genome of Drosophila melanogaster strain w1118; iso-2; iso-3. Fly 6(2):80-92

18. Lek M, Karczewski K, Minikel E, Samocha K, Banks E, Fennell T, O'Donnell-Luria A, Ware J, Hill A, Cummings B (2016) Analysis of protein-coding genetic variation in 60,706 humans. Nature 536(7616):285

19. Consortium GP (2010) A map of human genome variation from population scale sequencing. Nature 467(7319):1061

20. Tennessen JA, Bigham AW, O'Connor TD, Fu W, Kenny EE, Gravel S, McGee S, Do R, Liu X, Jun G (2012) Evolution and functional impact of rare coding variation from deep sequencing of human exomes. Science 337(6090):64-69

21. Kumar P, Henikoff S, Ng PC (2009) Predicting the effects of coding non-synonymous variants on protein function using the SIFT algorithm. Nat Protoc 4(7):1073-1081

22. Choi Y, Sims GE, Murphy S, Miller JR, Chan AP (2012) Predicting the functional effect of amino acid substitutions and indels. PLoS ONE 7(10):e46688

23. Adzhubei IA, Schmidt S, Peshkin L, Ramensky VE, Gerasimova A, Bork P, Kondrashov AS, Sunyaev SR (2010) A method and server for predicting damaging missense mutations. Nat Methods 7(4):248-249

24. Richards S, Aziz N, Bale S, Bick D, Das S, Gastier-Foster J, Grody WW, Hegde M, Lyon E, Spector E (2015) Standards and guidelines for the interpretation of sequence variants: a joint consensus recommendation of the American College of Medical Genetics and Genomics and the Association for Molecular Pathology. Genet Med 17(5):405

25. Robinson JT, Thorvaldsdóttir H, Winckler W, Guttman M, Lander ES, Getz G, Mesirov JP (2011) Integrative genomics viewer. Nat Biotechnol 29(1):24-26

26. Team RC (2013) R: a language and environment for statistical computing. R Foundation for Statistical Computing, Vienna

27. Molinaro V, Pensotti V, Marabelli M, Feroce I, Barile M, Pozzi S, Laghi L, Serrano D, Bernard L, Bonanni B (2014) Complementary molecular approaches reveal heterogeneous CDH1 germline defects in Italian patients with hereditary diffuse gastric cancer (HDGC) syndrome. Genes Chromosom Cancer 53(5):432-445

28. Masciari S, Larsson N, Senz J, Boyd N, Kaurah P, Kandel MJ, Harris LN, Pinheiro HC, Troussard A, Miron P (2007) Germline E-cadherin mutations in familial lobular breast cancer. J Med Genet 44(11):726-731

29. Frebourg T, Oliveira C, Hochain P, Karam R, Manouvrier S, Graziadio C, Vekemans M, Hartmann A, Baert-Desurmont S, Alexandre C (2006) Cleft lip/palate and CDH1/E-cadherin mutations in families with hereditary diffuse gastric cancer. J Med Genet 43(2):138-142

30. Vogelaar IP, Figueiredo J, van Rooij IA, Simões-Correia J, van der Post RS, Melo S, Seruca R, Carels CE, Ligtenberg MJ, Hoogerbrugge $N$ (2012) Identification of germline mutations in the cancer predisposing gene $\mathrm{CDH} 1$ in patients with orofacial clefts. Hum Mol Genet 22(5):919-926

31. Hansford S, LiChang H, Kaurah P, Woo M, Shumansky K, Schaeffer DF, Corso G, Zogopoulos G, Gallinger S, Pinheiro H (2014) Genetic basis of hereditary gastric cancer: beyond the CDH1 locus. Can Res 74(19 Supplement):1282-1282 
32. Kaurah P, MacMillan A, Boyd N, Senz J, De Luca A, Chun N, Suriano G, Zaor S, Van Manen L, Gilpin C (2007) Founder and recurrent $\mathrm{CDH} 1$ mutations in families with hereditary diffuse gastric cancer. JAMA 297(21):2360-2372

33. Brooks-Wilson A, Kaurah P, Suriano G, Leach S, Senz J, Grehan N, Butterfield Y, Jeyes J, Schinas J, Bacani J (2004) Germline E-cadherin mutations in hereditary diffuse gastric cancer: assessment of 42 new families and review of genetic screening criteria. J Med Genet 41(7):508-517

34. Levy-Lahad E, Catane R, Eisenberg S, Kaufman B, Hornreich G, Lishinsky E, Shohat M, Weber BL, Beller U, Lahad A (1997) Founder BRCA1 and BRCA2 mutations in Ashkenazi Jews in Israel: frequency and differential penetrance in ovarian cancer and in breast-ovarian cancer families. Am J Hum Genet 60(5):1059

35. King M-C, Marks JH, Mandell JB (2003) Breast and ovarian cancer risks due to inherited mutations in BRCA1 and BRCA2. Science 302(5645):643-646

36. Warner E, Foulkes W, Goodwin P, Meschino W, Blondal J, Paterson C, Ozcelik H, Goss P, Allingham-Hawkins D, Hamel N
(1999) Prevalence and penetrance of BRCA1 and BRCA2 gene mutations in unselected Ashkenazi Jewish women with breast cancer. J Natl Cancer Inst 91(14):1241-1247

37. Moslehi R, Chu W, Karlan B, Fishman D, Risch H, Fields A, Smotkin D, Ben-David Y, Rosenblatt J, Russo D (2000) BRCA1 and BRCA2 mutation analysis of 208 Ashkenazi Jewish women with ovarian cancer. Am J Hum Genet 66(4):1259-1272

38. McLaughlin J, Dryer D, Logan H, Mao Y, Marrett L, Morrison H, Schacter B, Villeneuve G, Waters C, Semenciw R (2006) Canadian cancer statistics 2006. National Cancer Institute of Canada, Toronto

39. da Silva Tatley F, Aldwell FE, Dunbier AK, Guilford PJ (2003) $\mathrm{N}$-terminal E-cadherin peptides act as decoy receptors for Listeria monocytogenes. Infect Immun 71(3):1580-1583

40. Hamon M, Bierne H, Cossart P (2006) Listeria monocytogenes: a multifaceted model. Nat Rev Microbiol 4(6):423-434

41. Pentecost M, Otto G, Theriot JA, Amieva MR (2006) Listeria monocytogenes invades the epithelial junctions at sites of cell extrusion. PLoS Pathog 2(1):e3 